9. Schmidt AM, Hori O, Chen JX et al. (1995) Advanced glycation endproducts interacting with their endothelial receptor induce expression of vascular cell adhesion molecule-1 (VCAM-1) in cultured human endothelial cells and in mice. A potential mechanism for the accelerated vasculopathy of diabetes. J Clin Invest 96: 1365-1403
10. Pujia A, Gnasso A, Irace C, Colonna A, Mattiolo PL (1994) Common carotid arterial wall thickness in NIDDM subjects. Diabetes Care 17: 1330-1336

\section{Increased levels of plasma ELAM-1, ICAM-1 and VCAM-1 in NIDDM: possible role of oxidized LDL}

\section{Dear Sir,}

Dr. Fasching et al. report very interesting data on circulating adhesion molecules in non-insulin-dependent diabetic (NIDDM) patients. Intercellular adhesion molecule-1 (ICAM-1), vascular cell adhesion molecule-1 (VCAM-1), and endothelial leukocyte adhesion molecule-1 (ELAM-1) were analysed in a large group of NIDDM patients $(n=159)$ and age-matched healthy subjects $(n=71)$. Circulating concentrations of ICAM-1, VCAM-1 and ELAM-1 were found to be elevated by 36,14 and $70 \%$ respectively in NIDDM patients vs the control subjects. Given the high number of subjects studied, the authors were also able to calculate that the percentage of NIDDM patients exceeding the respective normal range were $25 \%$ for ICAM- $1,11 \%$ for VCAM- 1 and $30 \%$ for ELAM-1. The results presented by Fasching et al. are in agreement with and strongly support the data previously reported by Steiner et al. [1] and Cominacini et al. [2].

In agreement with our results [2] and in disagreement with the paper of Steiner et al. [1], Dr. Fasching et al. found a weak correlation between ELAM-1 concentration and glycaemic control. They attributed the weakness of this correlation $(r=0.19, p<0.02)$ to interfering metabolic abnormalities. Unfortunately, in this study, the authors speculate on the possible role of oxidized LDL and advanced glycation end products, but do not consider the simplest metabolic and non-metabolic abnormalities that could be the cause. Recent papers, for instance, demonstrated that hypertension [3] and dyslipidaemia [2] are pathological conditions which are also characterized by increased levels of plasma ELAM-1.

Dr. Fasching et al. considered increased oxidation of LDL or formation of advanced glycation end products to be the metabolic aberrations that could interfere with the correlation between ELAM-1 and glycaemic control.

As far as the increased oxidation of LDL is concerned, there is now data to demonstrate that the susceptibility of LDL to oxidation is increased in patients at risk of developing, or with established, atherosclerotic disease [4]. An increased susceptibility to LDL oxidation has also been shown in diabetic patients [5]. Even if 'susceptibility to LDL oxidation' is a semantic term that has never been clearly defined, and no general consensus exists as to how it should be determined, it may be related to the oxidation of LDL in the subendothelial space in vivo. Previous studies have shown that LDL tends to accumulate in areas of predilection in cholesterol-fed animals and that its residence time is increased [6]. This increase might allow for cellular oxidation of the LDL and the extent of this

Corresponding author: Dr. L. Cominacini, Istituto di Semeiotica e Nefrologia Medica, Università di Verona, Ospedale Policlinico, I-37134 Verona, Italy process may be dependent on its susceptibility to oxidation. This view is supported by the presence in atheromatous lesions of LDL with characteristics similar to those of oxidatively modified LDL [7]. The mechanism by which oxidized LDL can accelerate the atherogenic process is unknown. Studies using cultured cells have demonstrated that oxidized LDL is chemotactic for monocytes and stimulates monocyte endothelial interactions [8]. Furthermore, Khan et al. [9] have recently demonstrated that modified LDL augments cytokine-activated VCAM-1 gene expression in human vascular endothelial cells. There may be a relation, therefore, between oxidized LDL and expression of some adhesion molecules. Future studies on the correlation between the susceptibility of LDL to oxidation and the concentration of soluble adhesion molecules in diabetic patients are required.

Yours sincerely,

L. Cominacini, U. Garbin, A. Fratta Pasini, V. Lo Cascio

\section{References}

1. Steiner M, Reinhardt KM, Krammer B, Ernst B, Blann AD (1994) Increased levels of soluble adhesion molecules in type 2 (non-insulin dependent) diabetes mellitus are independent of glycaemic control. Thromb Haemost 72: 979-984

2. Cominacini L, Fratta Pasini A, Garbin U et al. (1995) Elevated levels of soluble E-selectin in patients with IDDM and NIDDM: relation to metabolic control. Diabetologia 38: 1122-1124

3. Blann AD, Tse W, Maxwell SJR, Waite MA (1994) Increased levels of the soluble adhesion molecule E-selectin in essential hypertension. J Hypertension 12: 925-928

4. Cominacini L, Garbin U, Pastorino M et al. (1993) Predisposition to LDL oxidation in patients with and without angiographically established coronary artery disease. Atherosclerosis 99: 63-70

5. Cominacini L, Garbin U, Pastorino AM et al. (1994) Increased susceptibility of LDL to in vitro oxidation in patients with insulin-dependent and non-insulin-dependent diabetes mellitus. Diab Res 26: 173-184

6. Schwenke DC, Carew TE (1987) Determination of the LDL degradation rate, content and residence time in lesioned and non lesioned aorta. Circulation 76 [Suppl IV]: 313

7. Palinsky W, Yla-Herttuala S, Rosenfeld ME, Butler SW, Socher SA, Parthasarathy S (1990) Antisera and monoclonal antibodies specific for epitopes generated during oxidative modification of low density lipoprotein. Arteriosclerosis 10: $325-332$

8. Liao F, Berliner JA, Mehrabian M et al. (1991) Minimally modified low density lipoprotein is biologically active in vivo in mice. J Clin Invest 87: 2253-2257

9. Khan BV, Parthasarathy S, Alexander RW, Medford RM (1995) Modified low density lipoprotein and its constituents augment cytokine-activated vascular cell adhesion molecule-1 gene expression in human vascular endothelial cells. J Clin Invest 95: 1262-1270 